\title{
Transition-To-Adulthood Profiles and Well-Being: Similarities and Distinctions Among Urban and Remote Contexts.
}

\author{
Stéphanie Boisvert ${ }^{1,2}$, Jacinthe Dion ${ }^{1,2}$, François Poulin ${ }^{4}$, Marie-Ėve Blackburn ${ }^{2,3}$, \\ Marie-Christine Brault ${ }^{1,2}$, Marco Gaudreault ${ }^{3}, \&$ Julie Auclair $^{3}$
}

${ }^{1}$ Intersectoral Center for Sustainable Health at Université du Québec à Chicoutimi, Health Sciences

${ }^{2}$ UQAC-Cégep de Jonquière's VISAJ Research Chair on youth's living conditions, health, adjustment and aspirations

${ }^{3}$ ÉCOBES - Research and transfer at Cégep de Jonquière

${ }^{4}$ Department of psychology, Université du Québec à Montréal

This is a pre-copyedited, author-produced version of an article accepted for publication following peer review. The final published version is available online with the following doi : https://doi.org/10.1177/2167696820983040

For citation: Boisvert, S., Dion, J., Poulin, F., Blackburn, M.-E., Brault, M.-C., Gaudreault, M., \& Auclair, J. (2020). Transition-To-Adulthood Profiles and Well-Being: Similarities and Distinctions Among Urban and Remote Contexts. Emerging adulthood. https://doi.org/10.1177/2167696820983040

Conflict of Interest: All authors declare that they have no conflicts of interest.

Stéphanie Boisvert, Ph.D., Postdoctoral fellow, corresponding author

Université du Québec à Chicoutimi

Pavillon des sciences de la santé

Département des sciences de la santé

Bureau V2-1140

555 , boulevard de l'Université

Chicoutimi (Québec) G7H 2B1

E-mail: stephanie.boisvert@outlook.com 


\begin{abstract}
In this study, two different contexts were examined to identify and describe transition-toadulthood profiles at age 25 (based on four adulthood markers) and to determine whether these profiles differ in well-being at age 25. Two French-Canadian samples (urban sample, $n=321$; remote sample, $n=363$ ) completed questionnaires at age 25 regarding adulthood markers (having left school, being a parent or expecting a child, having left the parental home, and being in a romantic relationship) and well-being (depressive symptoms, alcohol use, and self-esteem). A person-centered approach helped determine the presence of five distinct profiles for both samples: workers, parents, independent students, singles, late bloomers. The results indicated similarities and differences between contexts regarding the experience of transition to adulthood and demonstrated that youth's well-being is associated with their profile and their context. This study contributes to the literature on emerging adulthood by describing heterogeneity in the transition to adulthood.
\end{abstract}

Key Words: Emerging Adulthood; Transitions to Adulthood; Well-Being; Life Events; Quantitative Methods 


\section{Transition-To-Adulthood Profiles and Well-Being:}

\section{Similarities and Distinctions Among Urban and Remote Contexts.}

Some youth tend to take more time than their parents and grandparents did to enter adulthood (e.g., Vespa, 2017). This extended time span between adolescence and adulthood (around ages 18-29) characterizes "emerging adulthood," a greatly heterogeneous developmental period where youth are generally expected to attain important developmental tasks before entering adulthood: independence, involvement in a stable romantic relationship, and involvement in the workforce (Arnett, 2004). Adulthood markers can be objective, such as parenthood or marriage (e.g. Lee et al., 2018) or individualistic, such as feeling like an adult (e.g. Manning et al., 2010). However, there is no consensus regarding which adulthood markers are the most relevant to describe these adulthood tasks, possibly because these markers are partially context-dependent (Rankin \& Kenyon, 2008). To our knowledge, there have been no studies where transition-to-adulthood profiles have been identified in the distinct context of the Quebec population, where only $1.8 \%$ of men and $2.3 \%$ of women aged 30 years were married in 2018 (Institut de la statistique du Québec [ISQ], 2019). Furthermore, little is known about how wellbeing is associated with these multiple profiles. In this study, we aimed to identify and compare transition-to-adulthood profiles in two different samples representing urban and remote contexts of a Quebec population and to examine well-being differences among these profiles.

\section{Transition to Adulthood}

Whereas emerging adulthood is a developmental period of exploration, experimentation, instability, self-focus, and feeling in-between (Arnett, 2004), adulthood is a period of stability, autonomy, and responsibilities (Galland, 2000). Social clock theory states that, in every developmental period, there is an optimal age window for developmental tasks (Lehnart et al., 2010). There are individual and contextual differences in people's development compared with the norm, which generally indicate how they are progressing in their life course development (McCormick et al., 2011), such as when a person becomes an adult. The importance attributed to adult roles are context-dependent; in other words, it varies according to social and demographic contexts (Cepa \& Furstenberg, 2020). For example, Rankin and Kenyho (2008) found that youth in traditional contexts attribute more importance than youth in less traditional contexts to adult roles: graduation, marriage, parenthood, long-term career, home purchase, or full-time employment.

To examine the transition to adulthood, it is crucial to first find important adulthood markers according to the context of the study. In the specific context of Quebec, a vast territory, 
there are some remote aeras with fewer options of higher educational paths because universities are smaller or even non-existent. This creates three educational situations: an exodus to metropolises by youth wishing to attend university programs that are otherwise unavailable, shorter educational paths for youth choosing to stay in their home town, and paths similar to those living in urban contexts, where university programs are available near their home town. Therefore, a first important adulthood markers is whether youth are still in school or not, which would be more inclusive than the "college completion" variable since not all youth have the same access to higher education. For most youth, having graduated is usually an important step toward involvement in the work sphere (Oxford et al., 2010), whereas extended studies could delay other adult roles such as having children (Shek et al, 2020). This may be particularly true for youth who paused or stopped romantic relationships to pursue their educational path. Considering this context and the fact marriage is rare among any Quebec's regions, simply being in a romantic relationship may be a better indicator than marriage of involvement in the romantic sphere. Another important marker of adulthood is leaving the parental home. Whatever youth's reasons for leaving home, it is an important life event associated increased responsibilities and accelerated adulthood (Mulder \& Clark, 2002; Burngruber, 2016), whereas postponement of departure from home is associated with delayed process of becoming independent (Roisman et al., 2004) and decreased romantic involvement (Seiffe-Krenke, 2009). A final relevant indicator of adulthood is parenthood. Becoming a parent comes with great responsibilities and is known to accelerate the attainment of other adulthood markers, such as leaving the family nest (Goldscheider et al., 2014). In Quebec, the mean age for a first child was 29.1 years in 2018 (ISQ, 2019).

Supplementary transition-to-adulthood profiles differences should also be examined. For example, adulthood markers are reached faster when one's career requires no extended-schooling or a short-term educational path (Shulman et al., 2013). Therefore, educational levels should be considered to potentially play a role in the attainment of other adulthood markers. Employment and full-time work are two other variables linked to independence (Mandell \& Klein, 2009), which is one of the main tasks of emerging adulthood (Manning et al., 2010). However, even if these variables are informative in this regard, they do indicate if youth feel independent. Therefore, it is relevant to ask them if they feel that their current job is stable or simply that they feel financially independent (Butterbaugh et al., 2019).

Another important step when studying transition to adulthood is to capture heterogeneity. The use of a person-centered approach is crucial to describe distinct profiles regarding the attainment of adulthood indicators (Tagliabue et al., 2016). This sort of analysis groups 
homogeneous individuals from a heterogeneous sample, making it possible to describe individual differences (Bardoshi et al., 2020). Some studies used person-centered analyses and found different profiles of transition to adulthood. For example, Lee et al. (2018) questioned a sample of 14,503 youths over 13 years old $\left(\mathrm{M}_{\mathrm{age}}\right.$ in $1995=15.5$ years $)$. Using a finite mixture model, they described the sequence and timing of four major life transition events: college graduation, fulltime work, marriage, and parenthood. Four transition patterns were found: Traditional transition (college graduation, full-time work, marriage, then family formation; 7.8\%), Early work and early family (early full-time work, early family formation, marriage, then college graduation; 21.4\%), Work and education (full-time work, college graduation, then marriage and family formation; 21.9\%), Early work and then family (early full-time work, family formation, marriage, college graduation; 48.9\%). They also found that women were more likely to form a family early. In another recent study, Galanaki and Sideridis (2019) examined 814 Greek university students (Mage $=19.9, S D=1.41)$. Using a latent class analysis with 15 adulthood markers, such as "feeling inbetween" or "commitment making," they found five profiles: Immature explorers (29.58\%), Anxious explorers in-between (29.90\%), Emerging adults (18.30\%), Adult committers (12.58\%), Blocked in transition (9.64\%). The results showed that youth with profiles characterized by more adulthood predictors tended to be women, to live on their own, to be in a romantic relationship, and to have with fewer financial constraints. While these results shed light on the heterogeneity in the sequence and timing of transitions, there is lack of information about youth's well-being of the transition profiles and some of the examined markers are not suitable for the Quebec context.

\section{Well-Being Among Transition-To-Adulthood Profiles}

Becoming an adult may be more difficult for some and easier for others. The importance of describing and understanding the well-being of youth in association with their transition-toadulthood profile is undeniable. Mental health issues are more common among emerging adults than among any other adult group (Tanner et al., 2007). The four-part model of autonomy (Beyers et al., 2003) suggests that developmental tasks in emerging adulthood can sometimes be challenging and impact well-being (Lamborn \& Groh, 2009). Therefore, well-being —including depressive symptoms, alcohol use, and self-esteem — during the transition to adulthood should be investigated. Research has indicated that emerging adults report high rates of depressive symptoms and alcohol use (Bordeleau \& Joubert, 2017). Those rates are even higher for youth who tend to exhibit more features of emerging adulthood (identity exploration, experimentation, instability, self-focus, and feeling in-between; Lanctôt \& Poulin, 2018). Fortunately, the prevalence of mental health issues seems to decrease as youth reach adulthood indicators. For example, depressive 
symptoms and alcohol use tend to be lower among youth who are independent from their parents (Copp et al., 2015; Serido et al., 2018). Alcohol use tends to be lower also among emerging adults who are in a romantic relationship, and even lower for those living with a romantic partner (Fleming et al., 2010). Furthermore, although self-esteem is generally low in adolescence, it tends to increase in emerging adulthood as youth's self-knowledge and self-appreciation improve (Wagner et al., 2013; Erol \& Orth, 2011). Research has shown a positive association between selfesteem and romantic involvement, another important task of adulthood (Lehnart et al., 2010).

\section{The Present Study}

This study had two main objectives: 1) identify the various profiles of transition to adulthood at age 25 and compare them in two different Quebec contexts and 2) determine whether these profiles differ in well-being at age 25 (e.g., depressive symptoms, alcohol use, and selfesteem). Since this age is conceptually the middle of emerging adulthood (Arnett, 2004) and even may be the beginning of a subperiod in emerging adulthood (Nelson, 2020), a certain proportion of youth were expected to have attained some adulthood markers. We thus hypothesized that we could find both ends of the continuum of adulthood marker attainment: youth characterized by every examined adulthood marker and youth characterized by none of the examined markers. Furthermore, even if attainment of adulthood markers may change even after age 25 (Biggart \&

Walther, 2006), examining this particular age window was expected to provide important information on heterogeneity in youth's lives at this mid-point.

\section{Methods}

The data presented in this article were drawn from two longitudinal studies of youth that took place in one remote and one urban region of Quebec (French province in Canada). The procedures and questions used in each sample were similar enough to test the same research questions.

\section{Participants}

Participants in the urban sample were from the third most populated region of Quebec (473,400 residents), where higher education institutions are easily accessible (e.g., seven universities nearby). For this study, participants were questioned at age 25 in 2014 ( $S D=0.41 ; N$ $=321 ; 60.75 \%$ female; $26.79 \%$ had a university degree). This sample is derived from a 13 -year longitudinal study that took place in $2001\left(N=390 ; 57 \%\right.$ female; $\left.M_{\mathrm{age}}=12.38\right)$. Youth were recruited from twelve French-speaking schools. The sample was homogeneous on ethnic and sociodemographic variables, as most of the participants were white and Canadian-born (90\%), lived with both biological parents $(72 \%)$, came from middle-class families (mean family income 
$=\$ 45 \mathrm{k}-55 \mathrm{k}$ ), and had parents with the same average number of years of schooling (around 13 years).

Participants in the remote sample were from a non-metropolitan region, which was geographically isolated (fewer higher education institutions, e.g. one university nearby), ethnically and linguistically homogeneous (98.5\% Francophone), but still populous (277,298 residents). For the current study, participants were questioned at age 25 in 2012 ( $S D=0.30 ; N=363 ; 65.84 \%$ female; $30.85 \%$ had a university degree). The sample was derived from a 11-year longitudinal study that took place in $2002\left(N=605 ; 55 \%\right.$ girls, $\left.M_{\text {age }}=14.04\right)$.

\section{Procedures}

Participants from both samples completed a self-reported questionnaire online (respectively $0 \%$ and $94.3 \%$ ), on paper by mail (respectively $1.6 \%$ and $5.7 \%$ ), or at home under supervision of a trained research assistant (respectively $98.4 \%$ and $0 \%$ ). All provided written consent. Those in the urban sample received monetary compensation for their participation and those in the remote sample could participate in a drawing for several gift cards and iPad. These studies were approved by the Institutional Review Board for Ethics in Research with Humans (blinded for review).

\section{Measures}

Measures were almost the same in the two samples (see Table 1 for a descriptive comparison of each variable for both samples), which allowed us to compare the results.

\section{Identification and Validation of the Profiles}

Participants from both samples answered (yes/no) the following questions used as indicators of the transition to adulthood as recommended by Shanahan et al. (2005): "Are you currently in school?", "Do you have one or more children or are you (or your partner) currently pregnant?", "Do you believe you have permanently left your parental home?", "Do you currently have a romantic partner or are you dating someone?"

Once profiles are identified, it is recommended to validate them using external variables, that is, variables that can be strongly associated with the profiles, but different from the grouping variables (Lee et al., 2010). Five variables fit that description and were therefore used for external validation of the profiles in both samples: employment, number of work hours per week, feeling of having a stable job, feeling financially independent (only for the urban sample), and education level. All participants indicated whether they were currently employed and the number of hours spent at work per week (those without a job received a score of 0 work hours per week). Regarding job stability, participants from the non-urban sample reported the extent to which they agreed with 
the following sentence: "I plan to stay at my job for many years," ranging from 1 ("totally disagree") to 5 ("totally agree"). Participants from the urban sample answered this question: "Do you consider your job like...”. The choices were: “1) a temporary job [to make money”], “2) a step-toward-my-career job," or “3) a long-term job [my career]". Financial independence in the urban sample was assessed with the following question: "From a financial perspective, do you consider yourself..."; choices ranged from 1 ("Completely dependent") to 3 ("Completely independent"). They were asked about the highest education level attained. Answers were recoded into an interval scale ranging from 0 ("no diploma") to 4 ("university degree"). Gender was examined as a descriptive variable.

\section{Well-Being in Emerging Adulthood}

The well-being variables included were alcohol use, depressive symptoms, and self-esteem. For both samples, alcohol use was assessed with the following question: "In the last twelve months, how often have you consumed alcohol (beer, wine, or spirits)?”, ranging from 0 (“Rarely or never”) to 4 ("four times or more in a week).

Depressive symptoms were assessed with the 14-item Psychiatric Symptom Index (Ilfeld, 1976; French-version validated by ISQ, 1995) in the remote sample. Participants were asked how often they had experienced certain symptoms, such as feeling lonely or crying easily, in the last week on a scale from 1 ("Never") to 4 ("Very often"). All items were summed; high scores indicated high levels of depressive symptoms $(\alpha=.88 ;\rceil=.91)$. For the urban sample, depressive symptoms within the past week were assessed with the 13-item depression subscale of the Symptom Checklist-90-Revised (SCL-90-R, Wright et al., 2005; French-version validated by Tatu et al., 1994). Answers ranged from 1 ("not at all") to 5 ("Extremely"). The mean score was computed; higher scores indicated higher levels of depressive symptoms $(\alpha=.87 ;\rceil=.90)$.

Self-esteem was measured using the Rosenberg's Self-Esteem Scale (Rosenberg et al., 1995; French-version validated by Vallières \& Vallerand, 1990) in the remote sample, a 10-item questionnaire with a response scale ranging from 1 ("Totally disagree") to 4 ("Totally agree"). Some items were reverse coded, then all items were summed. A higher score reflected better selfesteem $(\alpha=.86 ;\rceil=.86)$. For the urban sample, self-esteem was measured with the Global SelfWorth Subscale of the Adult Perception Profile (Harter \& Messer, 1986; French-version validated by Bouffard et al., 2002), a five-item scale with questions like "Some adults are disappointed in themselves BUT other adults are at peace with themselves." Responses ranged from 1 ("Totally like me") to 4 ("BUT... totally like me"). A mean score was computed, a higher score reflecting higher self-esteem $(\alpha=.88 ;\rceil=.88)$ 


\section{Data Analysis Plan}

To better capture similarities and distinctions among both samples (urban and remote contexts), analyses were conducted in the same four steps for each sample: (1) preliminary and descriptive analyses, (2) identification of profiles of transition to adulthood, (3) validation of the identified profiles, (4) examination of youth's well-being differences among profiles.

\section{Preliminary and Descriptive Analyses}

First, all variables were examined for missing data and outliers in both samples. Missing values were rare in both samples (maximum 1\% of missing observations) and could therefore be considered inconsequential (Schafer, 1999). No extreme data (or outliers) were deleted, because these were rare and logical. Second, a series of descriptive analyses was performed on all selected variables for both samples (remote versus urban). The percentages, means, and standard deviations are presented in Table 1.

\section{Identifying the Profiles}

A TwoStep cluster analysis was performed with SPSS 22 to identify profiles of transition to adulthood using four dichotomous adulthood markers: (1) having left school, (2) being a parent (or expecting a child), (3) having left the parental home, and (4) being in a romantic relationship. At least 120 participants in each sample were needed for this analysis, since the minimum sample size is 30 times the number of clustering variables (Dolnicar et al., 2016). This analysis is comparable to other clustering methods (see Kent et al., 2014). It combines nonhierarchical and hierarchical clustering in a sequence, includes several dichotomous variables, and explores the optimal number of homogeneous groups that stand out from a given sample (Tkaczynski, 2017). It automatically tests models ranging from 1 to 15 groups; although exploratory creation of groups stops automatically when the measure of distance is equal to zero. There were three reasons for choosing this analysis strategy. First, clustering analysis is a person-centered analysis rather than a variable-centered one, which was required because the transition to adulthood is a heterogeneous

phenomenon (e.g., Lee et al., 2018). Second, the two-step cluster analysis is an exploratory analysis, which was needed because the number of emerging adulthood profiles to expect was unknown. Third, clustering analysis is well-suited for the dichotomous grouping variables used in this study (Fonseca, 2013).

\section{Validation of the Transition Profiles}

When running a cluster analysis, internal and external validation of the solution is crucial (Marquand et al., 2016). For internal validation, two procedures were followed. First, even if the analysis suggested an optimal number of clusters, the model that best represented the sample 
needed to be determined using several indices: the Bayesian Information Criterion (BIC), the Akaike Information Criterion (AIC), the log-likelihood, and the practical usefulness of the results (Nagin, 2005). Second, chi-square analyses with adjusted standardized residuals were performed with the four clustering variables to ensure significant differences between clusters for each variable.

For external validation, subsequent analyses with external variables are required to compare differences between clusters (Bardhoshi et al., 2020). Chi-square analyses and a MANOVA with Tukey's post hoc were carried out with five variables: employment, number of work hours per week, job stability, financial independence (only for the urban sample), and education level.

\section{Youths' Well-Being in Each Transition Profile}

A MANOVA with Tukey's post hoc was used to examine the youth's well-being among the various profiles in both samples with the following variables: depressive symptoms, alcohol consumption, and self-esteem.

\section{Results}

\section{Profiles of Transition Toward Adulthood at Age 25}

The TwoStep cluster analyses yielded models ranging from one to 13 groups. For the sake of parsimony, Table 2 shows the BIC, AIC, and log-likelihood indices only for models ranging from two to seven groups. The results revealed that the five-class model was optimal for the two samples, because the BIC and AIC indices decreased only slightly after this model. In addition, the log-likelihood for the five-group solution had a greater distance between each group than the other solutions and was more relevant for the qualitative description of the profiles.

Table 3 presents the results for the differences between the profiles on the grouping variables. Table 4 presents all the results differences between profiles for gender and external validation variables for both samples. All external dichotomous variables analyzed with chi-square tests showed significant results, thus contributing to the validation of our five-profile model. MANOVAs on other external variables (number of work hours, feeling of having a stable job, feeling financially independent, education level) also revealed significant differences among profiles for the remote (Wilks' $\lambda=.75, \mathrm{~F}(4,300)=7.47, p<.001$; partial $\eta 2=0.09 ; 1-\beta$ (power) $=1.00)$ and urban $\left(\right.$ Wilks $^{\prime} \lambda=.74, F(4,290)=5.59, p<.001 ;$ partial $\eta 2=.07 ; 1-\beta$ (power) $\left.=1.00\right)$ samples.

The profiles will now be described one by one for both samples simultaneously. The first profile was the most prevalent (37.19\% for the remote sample, and $28.97 \%$ for the urban sample). 
Youth in this profile were no longer in school, did not have children, had left the parental home, and were in a romantic relationship. They were called Workers because they were almost all employed and worked the highest number of hours per week compared with the other groups. Youth in the second profile (14.88\% for the remote sample, and $13.08 \%$ for the urban sample) were named Parents because they had generally attained all the examined adulthood markers: they all had children (or were currently expecting a child), most were no longer in school, most had left the parental home, and most were in a romantic relationship. In both samples, women were overrepresented in this profile. Moreover, participants in this profile were among the least educated, were the most likely to feel financially independent in the urban sample, and, along with the Workers, were more likely to feel like they were in a stable job path. The third profile $(20.11 \%$ for the remote sample, and $10.59 \%$ for the urban sample) was called Independent Students, as the youth in this group were all in school, but no longer lived with their parents. The majority had no children but were in a romantic relationship. They were among the most educated. They were also characterized by a lower number of work hours per week, and in the remote sample, were less likely to have a job. They had some of the lowest scores for the feeling of being in a stable work path. The fourth profile (13.22\% for the remote sample, and $29.60 \%$ for the urban sample) represented Singles because, unlike the youth in the other profiles, they were all single. Almost none of them had children. However, between-sample differences emerged for this profile, beginning with the difference in proportion. Second, all Singles in the remote sample had left the parental home and were among the most educated participants, whereas only a minority of Singles in the urban sample had left the nest and were the least employed participants. Youth in the last profile $(14.60 \%$ for the remote sample, and $17.76 \%$ for the urban sample) were named Late Bloomers because they presented a higher tendency to live with their parents at age 25 . The majority of youth in that group were no longer in school and were in a romantic relationship. None had children. Compared with other groups, men of the remote sample were overrepresented in this profile. Between-sample differences emerged for this profile as well. First, Late Bloomers from the remote sample were among the least educated and least employed, whereas those from the urban sample were among the most educated. The results also indicated that Late Bloomers from the urban sample felt the least financially independent (examined only in this sample).

\section{Transition Profiles and Well-Being at Age 25}

The analyses revealed significant differences in well-being (depressive symptoms, alcohol use, and self-esteem) between the profiles in both the remote (Wilks' $\lambda=.90, \mathrm{~F}(4,362)=3.07, p$ $<.001 ;$ partial $\eta 2=0.03 ; 1-\beta$ (power) $=0.99)$ and urban $\left(\right.$ Wilks' $^{\prime} \lambda=.92, \mathrm{~F}(4,315)=2.30, p=.007$; 
partial $\eta 2=.03 ; 1-\beta$ (power) $=0.93$ ) samples. The results are reported in Table 5. Univariate effects showed that self-esteem did not differentiate the profiles. As for the two other variables, the post hoc analyses revealed that depressive symptoms were lower among Parents (remote sample) and higher among Late Bloomers (remote sample) or Singles (urban sample). For alcohol use, Parents in both samples and Lates bloomers (urban sample) drank less often, while Singles (remote sample) or Independent students (urban sample) drank the most frequently. 


\section{Table 1}

Percentages, Means and Standard Deviations for All Measures Among Both Samples

\begin{tabular}{|c|c|c|}
\hline & Remote sample & Urban Sample \\
\hline Is a woman $(\%)$ & 65.29 & 60.75 \\
\hline \multicolumn{3}{|l|}{ Clustering variables } \\
\hline Is no longer in school (\%) & 68.87 & 70.09 \\
\hline Is a parent or is expecting a child (\%) & 15.45 & 14.64 \\
\hline Has left the parental home (\%) & 84.83 & 61.99 \\
\hline Is in a romantic relationship (\%) & 80.06 & 69.16 \\
\hline \multicolumn{3}{|l|}{ Validation variables } \\
\hline Has a job $(\%)$ & 84.30 & 90.65 \\
\hline Number of work hours per week ( $M$ (s.d.)) & $29.30(16.62)$ & $32.80(16.19)$ \\
\hline Is in a stable work path $(\%)$ & 57.38 & 47.66 \\
\hline Feels financially independent (\%) & & 59.19 \\
\hline Education level $(M(\text { s.d. }))^{\mathrm{a}}$ & $2.75(1.16)$ & $2.52(1.20)$ \\
\hline \multicolumn{3}{|l|}{ Well-being variables } \\
\hline Depressive symptoms $(M \text { (s.d.) })^{\mathrm{a}, \mathrm{b}}$ & $20.15(16.43)$ & $1.38(0.50)$ \\
\hline Alcohol use $(M(\text { s.d. }))^{\text {a }}$ & $2.45(1.17)$ & $2.54(1.14)$ \\
\hline Self-esteem $(M(\text { s.d. }))^{\mathrm{a}, \mathrm{b}}$ & $33.76(4.51)$ & $2.24(0.27)$ \\
\hline
\end{tabular}

Note.

${ }^{\mathrm{a}}=\mathrm{A}$ higher score equals a higher level of the measured variable.

$\mathrm{b}=$ Instruments measured the same construct but yielded different total scores. 


\section{Table 2}

Results of Twostep Cluster Analysis for Models Ranging From Two to Seven Groups

\begin{tabular}{lccccccc}
\hline \multirow{2}{*}{ Number of groups } & \multicolumn{2}{l}{ Remote Sample } & & Urban Sample & \\
\cline { 2 - 3 } \cline { 6 - 8 } & BIC & AIC & LL & & BIC & AIC & LL \\
\hline 2 & 1039.67 & 1008.52 & 1.54 & & 1078.42 & 1048.25 & 1.86 \\
3 & 775.80 & 729.07 & 1.17 & & 859.18 & 813.92 & 1.16 \\
4 & 555.18 & 492.87 & 1.28 & & 673.65 & 613.31 & 1.29 \\
$\mathbf{5}$ & $\mathbf{3 8 7 . 4 3}$ & $\mathbf{3 0 9 . 5 4}$ & $\mathbf{2 . 6 6}$ & & $\mathbf{5 3 5 . 4 2}$ & $\mathbf{4 5 9 . 9 9}$ & $\mathbf{1 . 2 7}$ \\
6 & 339.10 & 245.64 & 1.15 & & 431.09 & 340.57 & 1.59 \\
7 & 299.91 & 190.87 & 1.42 & & 373.76 & 268.16 & 1.02 \\
\hline
\end{tabular}

Note. Boldface type indicates the selected model. BIC $=$ Bayesian Information Criterion; AIC $=$ Aikaike Information Criterion; LL = log-Likelihood. 


\section{Table 3}

Identification of the Transition Profiles in Two Contexts (Remote and Urban Samples)

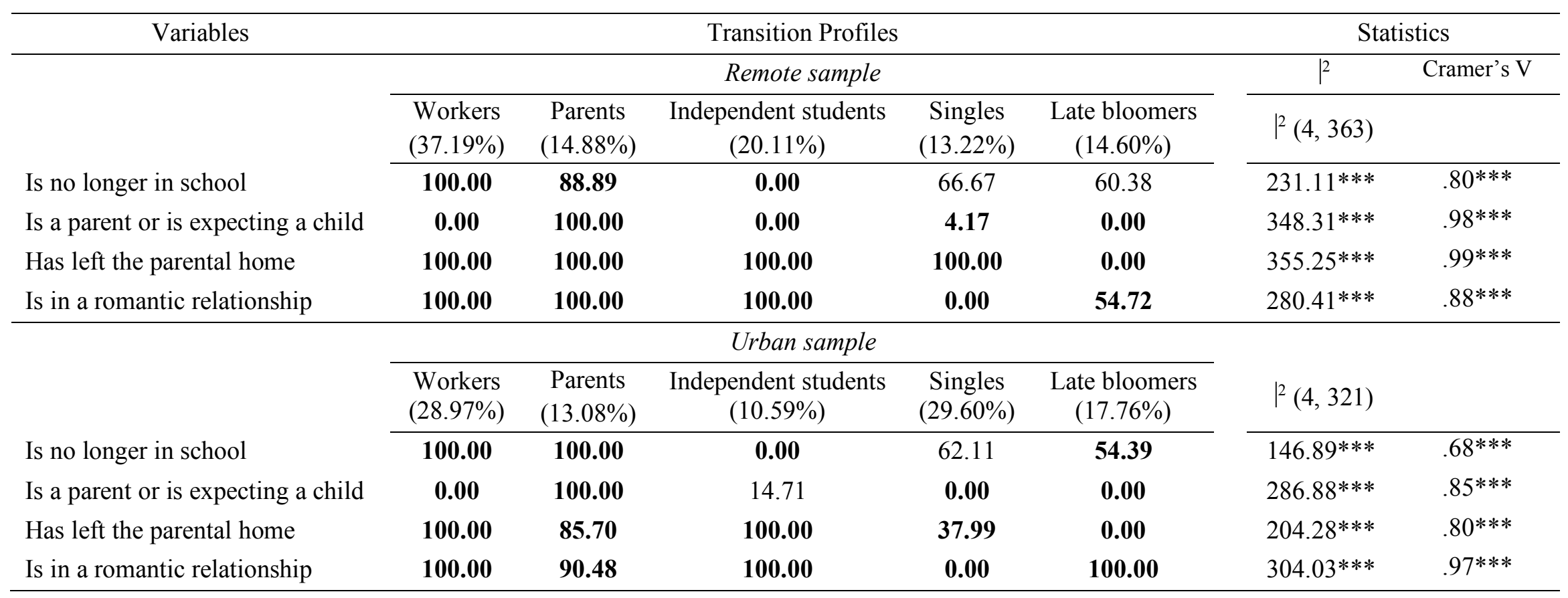

Note. Boldface type indicates standardized adjusted residuals higher than 2.00 or lower than -2.00 .

$* * *=p<.001$. 


\section{Table 4}

Description and Validation of the Transition Profiles in Two Contexts (Remote and Urban samples)

\begin{tabular}{|c|c|c|c|c|c|c|c|}
\hline \multirow[t]{2}{*}{ Variables } & \multicolumn{5}{|c|}{ Transition Profiles } & \multicolumn{2}{|c|}{ Statistics } \\
\hline & Workers & Parents & $\begin{array}{c}\text { Independent } \\
\text { students }\end{array}$ & Singles & Late bloomers & ${ }^{2}$ or $F$ & $\begin{array}{c}\text { Cramer's V or } \\
\text { partial } \eta 2\end{array}$ \\
\hline & \multicolumn{5}{|c|}{ Remote sample } & & \\
\hline Is a woman (\%) & 67.41 & 85.19 & 67.12 & 54.17 & 50.94 & $17.32 * *$ & $.22 * *$ \\
\hline Has a job (\%) & 97.78 & 79.63 & 65.75 & 87.50 & 73.58 & $42.08 * * *$ & $.34 * * *$ \\
\hline $\begin{array}{l}\text { Number of work hours per } \\
\text { week }(M \text { (s.d.)) }\end{array}$ & $39.10(10.05)_{\mathrm{a}}$ & $35.65(8.81) \mathrm{a}$ & $27.17(12.73)_{b}$ & $37.63(11.12)_{\mathrm{a}}$ & $33.39(10.47)_{\mathrm{a}}$ & $11.73 * * *$ & .14 \\
\hline $\begin{array}{l}\text { Feels in a stable work path } \\
(M \text { (s.d.)) }\end{array}$ & $3.85(1.18)_{a}$ & $3.70(1.32)_{\mathrm{a}}$ & $2.76(1.55)_{b}$ & $3.34(1.20)_{\mathrm{a}, \mathrm{b}}$ & $2.77(1.46)_{b}$ & $9.52 * * *$ & .11 \\
\hline \multirow[t]{2}{*}{ Education level (M (s.d.)) } & $2.78(1.10)_{\mathrm{a}, \mathrm{b}}$ & $2.60(0.96)_{a}^{a}$ & $3.28(1.00)_{\mathrm{b}}$ & $3.22(0.82)_{b}$ & $2.41(1.21)_{\mathrm{a}}$ & $5.71 * * *$ & .07 \\
\hline & \multicolumn{5}{|c|}{ Urban sample } & & \\
\hline Is a woman $(\%)$ & 61.29 & 83.33 & 67.65 & 53.68 & 50.88 & $13.99 * *$ & $.21 * *$ \\
\hline Has a job $(\%)$ & 96.77 & 85.71 & 85.29 & 85.26 & 96.49 & $12.03 *$ & $.19 *$ \\
\hline $\begin{array}{l}\text { Number of work hours per } \\
\text { week }(M \text { (s.d.)) }\end{array}$ & $39.95(12.17) \mathrm{a}$ & $38.42(5.78) a, b$ & $29.26(13.52)_{\mathrm{c}}$ & $36.39(14.29)_{\mathrm{ax}, \mathrm{b}}$ & $31.85(12.58)_{b, c}$ & $6.24 * * *$ & .08 \\
\hline $\begin{array}{l}\text { Feels in a stable work path } \\
(M \text { (s.d.)) }\end{array}$ & $2.64(0.62)_{a}$ & $2.69(0.67)_{a}$ & $2.00(0.80)_{b}$ & $2.10(0.82)_{b}$ & $2.00(0.85)_{b}$ & $12.05^{* * *}$ & .15 \\
\hline $\begin{array}{l}\text { Feels financially } \\
\text { independent }(M \text { (s.d.)) }\end{array}$ & $2.67(0.69)_{\mathrm{a}, \mathrm{b}}$ & $2.78(0.54)_{a}$ & $2.55(0.69)_{a, b, c}$ & $2.36(0.73)_{b, c}$ & $2.20(0.68)_{\mathrm{c}}$ & $6.29 * * *$ & .08 \\
\hline Education level ( $M$ (s.d.)) & $2.67(1.13)_{\mathrm{a}}$ & $1.97(1.00)_{\mathrm{b}}$ & $2.79(1.24)_{\mathrm{a}}$ & $2.52(1.18)_{\mathrm{a}, \mathrm{b}}$ & $2.70(1.22)_{\mathrm{a}}$ & $3.02 *$ & .04 \\
\hline
\end{tabular}

Note. Boldface type indicates standardized adjusted residuals higher than 2.00 or lower than -2.00 . Means sharing a common subscript are not significantly different at $\alpha=.01$ according to Tukey's post hoc.

$*=p<.05 . * *=p<.01 . * * *=p<.001$. 
Table 5

Means (and Standard Deviations) of the Well-Being Variables at Age 25 for Each Transition Profiles

\begin{tabular}{|c|c|c|c|c|c|c|c|}
\hline \multirow[t]{2}{*}{ Variables } & \multicolumn{5}{|c|}{ Transition Profiles } & \multicolumn{2}{|c|}{ Statistics } \\
\hline & Workers & Parents & $\begin{array}{c}\text { Independent } \\
\text { students }\end{array}$ & Singles & Late bloomers & $F$ & Partial $\eta 2$ \\
\hline & & & Remote sample & & & $F(4,362)$ & \\
\hline Depressive symptoms & $19.49(17.99)_{\mathrm{a}, \mathrm{b}}$ & $16.14(13.72)_{a}$ & $21.07(16.21)_{a, b}$ & $20.69(14.19)_{\mathrm{a}, \mathrm{b}}$ & $25.56(15.61)_{\mathrm{b}}$ & $2.41 *$ & .03 \\
\hline Alcohol use & $1.63(1.65)_{a, b}$ & $0.83(1.00)_{\mathrm{c}}$ & $1.45(1.50)_{\mathrm{a}, \mathrm{b}, \mathrm{c}}$ & $2.04(1.62)_{\mathrm{a}}$ & $1.11(1.36)_{b, c}$ & $5.43 * * *$ & .06 \\
\hline \multirow[t]{2}{*}{ Self-esteem } & $33.80(4.39)$ & $34.43(4.10)$ & $34.22(4.71)$ & $33.94(3.93)$ & $32.30(5.03)$ & 1.94 & .02 \\
\hline & \multicolumn{5}{|c|}{ Urban sample } & $F(4,315)$ & \\
\hline Depressive symptoms & $1.28(0.42)_{\mathrm{a}}$ & $1.38(0.46)_{\mathrm{b}}$ & $1.34(0.36)_{\mathrm{b}}$ & $1.53(0.60)_{\mathrm{c}}$ & $1.32(0.45)_{\mathrm{b}}$ & $3.61 * *$ & .05 \\
\hline Alcohol use & $1.88(1.27)_{\mathrm{a}, \mathrm{b}}$ & $1.45(1.38)_{\mathrm{b}}$ & $2.24(1.21)_{\mathrm{a}}$ & $1.81(1.26)_{\mathrm{a}, \mathrm{b}}$ & $1.50(1.06)_{\mathrm{b}}$ & $2.72 *$ & .03 \\
\hline Self-esteem & $2.22(0.27)$ & $2.19(0.27)$ & $2.22(0.27)$ & $2.26(0.28)$ & $2.26(0.23)$ & 0.80 & .01 \\
\hline
\end{tabular}

Note. Means sharing a common subscript are not significantly different at $\alpha=.01$ according to Tukey's post hoc.

$*=p<.05 . * *=p<.01 . * * *=p<.001$. 


\section{Discussion}

Recent statistics indicate a global tendency for youth to delay their entry into traditional adult roles (e.g., Vespa, 2017). In this study using two Quebec samples of different contexts (urban and remote contexts), five profiles of the transition to adulthood at age 25 were observed and compared by analyzing adulthood markers. Results indicated differences among profiles in terms of well-being at age 25. Similarities and distinctions among contexts are also discussed.

\section{Profiles of the Transition to Adulthood in a Remote and an Urban Context}

\section{Workers}

This profile represented approximately a third of the youth in both samples. They had much higher levels of involvement in the work sphere than the four other profiles. They were no longer in school, were the most employed, and worked more hours per week than the average for 25-yearold Quebeckers, which is 32 hours per week (ISQ, 2014) Furthermore, they were independent, having left the parental home and feeling stability in their work sphere. One major marker separating them from the Parents was not having entered parenthood. Nonetheless, it should be noted that not everyone wants to become a parent. Also, the average age at which Quebec women were having their first child in 2018 was 29.1 years (ISQ, 2019). Those who want children may have been waiting for some assurance regarding occupational stability and to be comfortably independent before entering family life (Popenoe \& Whitehead, 2001). That said, it is also possible that they had already been in the process of starting a family (e.g., miscarriages, previous or current attempts at having children as single parents), but this information was not measured. In another vein, Workers did not significantly stand out on well-being variables. However, when looking at means, Workers presented a tendency to have fewer depressive symptoms. This observation is not surprising, one study having indicated a negative association between depressive symptoms and a sense of having achieved developmental milestones (Kuwabara et al., 2007)

\section{Parents}

For both the urban and remote samples, the Parents were characterized by appearing particularly advanced in their transition to adulthood at age 25 , if not by already being in adulthood. They had attained the four examined adulthood markers, as most of them had finished school, had left the parental home, were in a romantic relationship, and were parents. The fact that women were overrepresented in this profile may explain this situation, since women tend to enter adulthood more quickly than men do (Oesterle et al., 2010). This is also true for young women in 
Quebec, since they generally leave the parental home and have children earlier than men do (ISQ, 2014b). Also, women tend more to invest themselves in the romantic sphere (Shulman et al., 2013). Finally, entry into adulthood may be easier when youth coordinate involvement in the romantic sphere and independence (Shulman \& Connolly, 2013). This means that youth approach adulthood when they have stable employment to which they feel committed and which provides them with satisfactory income, when they no longer live with their parents, and when they have a romantic relationship with a potential future. This coordination seemed very present among the youth in this profile, who had accomplished all the tasks associated with emerging adulthood.

Another particularity of the Parents was their positive well-being at age 25: they drank alcohol less frequently and presented fewer depressive symptoms than the youth in the other profiles. These results are consistent with the literature. Although adolescents in a romantic relationship consume more alcohol (Rouvès \& Poulin, 2016), being in a couple in emerging adulthood is a protective factor against problematic alcohol consumption (Rauer et al., 2016; Snyder \& Rubenstein, 2014). However, they could have presented a less positive well-being portrait than the one drawn here. According to the life course perspective, having a head start in accomplishing tasks associated with a developmental period may lead to negative well-being consequences, because the adoption of new roles could require skills or knowledge that the individual may have not yet acquired (Elder et al., 2015). In fact, it is important to stress that the individuals in this group had had at least one child before age 25, which is below the average age observed in the Quebec population (29.1 years; ISQ, 2019). The apparent absence of psychosocial risks may be explained by the fact that these youth felt stable in their work sphere and financially independent. Furthermore, although they had attained all the indicators of adulthood sooner than their peers, they met the traditional norms expected of adults in Western society.

\section{Independent Students}

The youth in this profile presented partial attainment of the examined adulthood markers at age 25 . They demonstrated some independence, having left the parental home. They reported some involvement in the romantic sphere, being in a romantic relationship, but most without children yet. Meanwhile, they felt less involved in the work sphere, probably because they were all still in school, tended to be less employed in the remote sample, and worked fewer hours per week than their peers. These lower levels of involvement in the work and family spheres may be explained by a greater investment in the academic sphere, considering that these participants were 
among the most educated. In fact, emerging adults pursuing university studies tend less to have career-oriented jobs or children at age 24 (Osgood et al., 2005). Moreover, the proportion of youth in this group (i.e., $19.66 \%$ for the remote sample, and $10.59 \%$ for the urban sample) is consistent with the demographic data from Quebec, which show that 13\% of Quebec youth are still in school between ages of 25 and 29 (ISQ, 2014). Consequently, some of the youth in this profile may have been studying for a master's or doctoral degree.

\section{Singles}

The youth in this profile were characterized by the fact that they were not engaged in the romantic sphere. However, they showed some level of independence because a certain proportion had left the parental home and most were working full time. However, they did not feel that their job was going to be stable in the near future, creating instability in this important sphere. It is possible that they were more invested in exploring the romantic and work spheres than their peers were, which is one of the main characteristics of the emerging adulthood period (Arnett, 2000). Youth who choose to explore these spheres would tend to delay taking on adult roles (Arnett, 2000), which seemed to be the case here. However, exploration presents a psychosocial risk and is associated with more problematic alcohol consumption and depressive symptoms (Lanctôt \& Poulin, 2018). Also, greater alcohol consumption by the youth in this profile may also be linked to their status as singles (Fleming et al., 2018). However, because only the Singles in the remote sample showed a higher frequency of alcohol use and only the Singles in the urban sample showed higher depressive symptoms, there may be context-related factors contributing to these well-being variables. In another vein, it is possible that the delay observed in their involvement in the romantic sphere was not necessarily their choice. In fact, some youth may attempt to invest in or explore the romantic sphere but without success. Gender may explain this. Boisvert and Poulin (2017) found that a romantic relationship pattern characterized by a delay in entering the romantic sphere is related to being a man and is associated with less advancement in the work sphere at age 25 .

\section{Late Bloomers}

Along with the Singles, youth in this profile were characterized by the fewest adulthood markers. They were named Late Bloomers because they presented a higher tendency to live with their parents at age 25. Most were no longer in school and most were in a romantic relationship. However, none had children. Compared with other groups, men were overrepresented in this profile. This result is not surprising, since gender is associated with the pace at which youth 
accomplish tasks related to emerging adulthood (Boisvert \& Poulin, 2017; Rauer et al., 2013). Regarding well-being, the Late Bloomers in the remote sample presented the highest levels of depressive symptoms. Some studies have drawn a parallel between high depressive symptom levels and low independence among emerging adults. For example, negative psychosocial consequences among emerging adults who lived with their parents and were unemployed were noted by Mortimer et al. (2017). The authors explained this finding by the importance of young adults having confidence in their own personal resources and being independent. These explanations seem plausible, since those youth also felt less independent. Between-sample differences also emerged for this profile. First, Late Bloomers from the remote sample were among the least educated and least employed, whereas those from the urban sample were among the most educated and most employed. The results also indicated that Late Bloomers from the urban sample were felt the least financially independent and less like they were in a stable work path. These differences may also be related to social and demographic characteristics of both samples.

\section{Influence of the Context}

Because transition to adulthood could be influenced by context-related factors (Cepa \& Furstenberg, 2020), youth from urban or remote contexts may have different opportunities regarding their transition to adulthood. For example, different educational opportunities among urban and remote youth can explain differences in attained adulthood markers at age 25 , such as leaving the parental home or being in a romantic relationship. Youth who leave their hometown to pursue higher education will have to leave the parental nest and might end or pause a romantic relationship. This scenario is less likely to occur for urban youth, who could attend almost any university program while staying in their parents' home and keeping their romantic partner. Since not all youth need or want to pursue higher education, these context differences may affect only a portion of youth. Our results support this idea. We found that Workers and Parents from both samples shared common experiences and well-being characteristics: most had finished school, and had reached almost all other adulthood markers. They felt good, felt independent, and were engaged in their job. Therefore, youth from those two profiles may have been less affected by context-related factors. However, we found some interesting differences for the Independent Students, Singles and Late Bloomers that we believe these context-related factors may explain. For example, Independent Students from the remote sample may have left their hometown and a romantic partner for school and may therefore have felt particularly serious about their educational 
path. This could explain why they tended to be less employed and to work fewer hours than other profiles, and why they drank alcohol less frequently whereas Independent Students from the urban sample tended to drink more frequently. This last result is consistent with studies reporting higher levels of alcohol use for college and university students (Kypri et al., 2005; Slutske, 2005). For the Singles, the main differences between contexts compared with the other profiles were that youth from the remote sample were among the most educated and drank alcohol more frequently. These results are not surprising, some studies having indicated more highly educated people tend to drink alcohol more often and that this would be particularly true for women (Huerta \& Borgonovi, 2010). For their part, Singles from the urban sample were more depressed. This finding is also consistent with current literature, where being in a romantic relationship is a protective factor for depression (Galambos et al., 2006). As for why the same variables did not stand out for both samples, context may be one explanation. Singles from the remote sample being among the most educated, their relationship status was more likely to be linked to their education path than that of Singles from the urban sample. The locus of control of the relationship status may have been external for youth from the remote sample, due to education, rather than internal, due to individual characteristics, therefore preserving their well-being. As for the youth in the urban sample, they may have been less inclined to leave their parents' home since they did not necessarily have to. However, one study indicated that depressive symptoms were more severe for emerging adults living with their parents and experiencing employment problems (Copp et al., 2015). Late Bloomers in the remote sample lived with their parents but had fewer "excuses" or motivations to leave than their peers: most of them were not in school, were not in a romantic relationship, and did not feel they had a stable job. They may have felt like they had "missed the boat" to go study elsewhere. All these elements combined led to the hypothesis that they may have felt somehow trapped in their life situation, which may explain their higher levels of depressive symptoms. Their situation seemed different from the Late Bloomers in the urban sample, who were more educated, perhaps because educational institutions were easily accessible. They were also in a romantic relationship. Rather than feeling trapped in their life situation, they may have been waiting for the right moment to leave, perhaps when they would feel more financially independent or find a stable job.

\section{Methodological, Theoretical, and Practical Contributions}

This study makes several methodological contributions. To begin, it is the first study to examine transition to adulthood in two Quebec contexts. Second, a person-centered approach was 
used and helped provide a much broader view of the differences between young adults in terms of types of transition toward adulthood at age 25. Even if samples were from different contexts, comparison of the samples indicated a relatively stable 5-profile model, which reinforces the confidence in the identified profiles. Third, we examined the well-being factors associated with the transition profiles at age 25 to better understand how the youth were doing according to their profile. The results definitely enhance the literature on the psychosocial health of youth.

\section{Limitations and Future Studies}

This study presents some limitations. The transition profiles were examined at one time point, which limits the understanding of stability of the indicators under study. For instance, had the Parents attained the indicators recently or at age 20? Had the Singles gone through a recent breakup or had they been single for a longer period? It is thus important to remain cautious when interpreting the results to not suggest that these profiles describe the entire period of emerging adulthood. Another limitation is the romantic involvement variable. Having a romantic partner and dating someone were combined even though these two relationships are different in terms of stability and linked to different psychosocial outcomes (Fincham \& Cui, 2010).

Future research would benefit from the continued study of the transition to adulthood. First, the indicators of adulthood attainment could be examined over several consecutive years, ideally over the entire period of emerging adulthood, to identify the various ways to transition to adulthood. Second, the individuals' psychosocial health should be studied once they are all adults to determine if certain transition profiles contribute positively to their health. Third, more qualitative components could be included so the youth could be asked about their experience with the transition and about their current intentions (e.g., start a family, move), which would help in understanding the finite differences between the groups. Finally, the transition profiles could be examined from other perspectives, notably the sociological perspective. This would contribute to understanding the role of macro-social factors (e.g., social or economic conditions) in the probability of belonging to certain profiles.

\section{Conclusion}

The literature on the transition to adulthood has been expanding since Arnett's (2000) conceptual proposal to consider emerging adulthood as a distinct developmental period (see Nelson, 2020). This study contributes to the literature by documenting the profiles of the transition

to adulthood in two different contexts of the Quebec population. The results obtained reflect the 
heterogeneity described by Arnett (2000) for the emerging adulthood period and underscore that transition to adulthood is interwoven with youth's contexts and linked to their well-being. 


\section{References}

Arnett, J. J. (2000). Emerging adulthood: A theory of development from the late teens through the twenties. American Psychologist, 55(5), 469-480. https://doi.org/10.1037/0003066X.55.5.469

Arnett, J. J. (2004). Emerging adulthood: The winding road from late teens through the twenties. Oxford University Press.

ASOPE Project(1973). Aspirations scolaires et orientations professionnelles des étudiants : Questionnaire destiné aux étudiants de Cégep 1. Université de Montréal.

Bardoshi, G., Um, B., \& Erford, B. T. (2020). Conducting a cluster analysis in counseling research: Four easy steps. Counseling Outcome Research and Evaluation, https://doi.org/10.1080/21501378.2020.1768522

Beyers, W., Goossens, L., Vansant, I., \& Moors, E. (2003). Structural model of autonomy in middle and late adolescence: Connectedness, separation, detachment, and agency. Journal of Youth and Adolescence, 32(5), 351-365. https://doi.org/10.1023/A:1024922031510

Biggart, A., \& Walther, A. (2006). Coping with yo-yo transitions: Young adults' struggle for support, between family and state in comparative perspective. In C. Leccardi \& E. Ruspini (Eds.), A new youth? Young people, generations and family life (pp. 41-62). Aldershot.

Boisvert, S., \& Poulin, F. (2017). Navigating in and out of romantic relationships from adolescence to emerging adulthood: Distinct patterns and their correlates at age 25. Emerging Adulthood, 5(3), 216-223, doi: 10.1177/2167696816675092

Bordeleau, M., \& Joubert (2017). La santé mentale des jeunes : certains consultant, d'autres pas. Qui sont-ils? Série Enquête sur la santé dans les collectivités canadiennes. Institut de la statistique du Québec. https://www.stat.gouv.qc.ca/statistiques/sante/bulletins/zoomsante-201706-62.pdf

Bouffard, T., Seidah, A., McIntyre, M., Boivin, M., Vezeau, C., \& Cantin, S. (2002). Mesure de l'estime de soi à l'adolescence: version canadienne-française du Self-Perception Profile for Adolescents de Harter [Measuring adolescent self-esteem: A French-Canadian version of Harter's Self-Perception Profile for Adolescents]. Canadian Journal of Behavioural Science / Revue canadienne des sciences du comportement, 34(3), 158-162. https://doiorg.sbiproxy.uqac.ca/10.1037/h0087167

Burngruber, A. (2016). Leaving the parental home as a transition marker to adulthood. In A. Furlong (Ed.), Routledge handbook of youth and young adulthood. Routledge international handbooks.

Butterbaugh, S. M., Ross, D. B., \& Campbell, A. (2019). My money and me: Attaining financial independence in emerging adulthood through a conceptual model of identity capital theory. Contemporary Family Therapy. https://doi.org/10.1007/s10591-019-09515-8

Cepa, K., \& Furstenberg, F. F. (2020). Reaching adulthood: Persistent beliefs about the importance and timing of adult milestones. Journal of Family Issues, 1-31. https://doi.org/10.1177/0192513x20918612

Copp, J. E., Giordano, P. C., Longmore, M. A., \& Manning, W. D. (2015). Living with parents and emerging adults' depressive symptoms. Journal of Family Issues, 38(16), 2254-2276. https://doi.org/10.1177/0192513x15617797

Dolnicar, S., Grün, B., \& Leisch, F. (2016). Increasing sample size compensates for data problems in segmentation studies. Journal of Business Research, 69(2), 992-999. https://doi.org/10.1016/j.jbusres.2015.09.004 
Elder, G. H., Jr., M. J. Shanahan, \& Jennings, J. H. (2015). Human development in time and place. In M. Bornstein \& T. Leventhal (Eds.), Ecological settings and processes in developmental systems, volume 4 of R. M. Lerner (Ed.), The handbook of child psychology and developmental science. Wiley.

Erol, R. Y., \& Orth, U. (2011). Self-esteem development from age 14 to 30 years: A longitudinal study. Journal of Personality and Social Psychology, 101(3), 607-619. https://doi.org/10.1037/a0024299

Fincham, F. D., \& Cui, M. (Eds.). (2010). Romantic relationships in emerging adulthood. Cambridge University Press.

Fleming, C. B., White, H. R., \& Catalano, R. F. (2010). Romantic relationships and substance use in early adulthood. Journal of Health and Social Behavior, 51(2), 153-167. https://doi.org/10.1177/0022146510368930

Fleming, C. B., Lee, C. M., Rhew, I. C., Ramirez, J. J., Abdallah, D. A., \& Fairlie, A. M. (2018). Disentangling between- and within-person associations using monthly assessments. $\begin{array}{lllll}\text { Substance Use } \quad \text { \& } & \text { 2240-2249. }\end{array}$ https://doi.org/10.1080/10826084.2018.1467455

Fonseca, J. R. S. (2012). Clustering in the field of social sciences: That is your choice. International Journal of Social Research Methodology, 16(5), 403-428. https://doi.org/10.1080/13645579.2012.716973

Galanaki, E., \& Sideridis, G. (2019). Dimensions of emerging adulthood, criteria for adulthood, and identity development in Greek studying youth: A person-centered approach. Emerging Adulthood, 7(6), 411-431.

Galambos, N. L., Barker, E. T., \& Krahn, H. J. (2006). Depression, self-esteem, and anger in emerging adulthood: Seven-year trajectories. Developmental Psychology, 42(2), 350-365. https://doi.org/10.1037/0012-1649.42.2.350

Galland, O. (2000). Entrer dans la vie adulte : Des étapes toujours plus tardives, mais resserrées. Économie et Statistique, 337 (1), 13-36. https://doi.org/10.3406/estat.2000.7494

Goldscheider, F. K., Hofferth, S. L., \& Curtin, S. C. (2014). Parenthood and leaving home in young adulthood. Population Research and Policy Review, 33(6), 771-796. https://doi.org/10.1007/s11113-014-9334-9

Harter, S., \& Messer, B. (1986). Manual for the Adult Self-Perception Profile. University of Denver.

Huerta, M., \& F. Borgonovi (2010). Education, alcohol use and abuse among young adults in Britain, OECD Education Working Papers, 50. https://doi.org/10.1787/5kmbqvsh57g0-en

Ilfeld, F. W. (1976). Further validation of a psychiatric symptom index in a normal population. Psychological Reports, 39(3), 1215-1228. https://doi.org/10.2466/pr0.1976.39.3f.1215

Institut de la statistique du Québec (1995). Et la santé, ça va en 1992-1993? Rapport de l'Enquête sociale et de santé 1992-1993 (volume 1). http://www.stat.gouv.qc.ca/statistiques/sante/etat-sante/sante-globale/ess_19921993_vol1.pdf

Institut de la statistique du Québec (2014). Regard statistique sur la jeunesse : État et évolution de la situation des Québécois âgés de 15 à 29 ans, 1996 à 2012. http://www.stat.gouv.qc.ca/statistiques/conditions-vie-societe/regard-jeunesse.pdf

Institut de la statistique du Québec (2014b). Coup d'oeil sociodémographique : Les naissances et les décès au Québec et dans les régions en 2013. 
http://www.stat.gouv.qc.ca/statistiques/population-demographie/bulletins/coupdoeilno32.pdf

Institut de la statistique du Québec (2019). Le bilan démographique du Québec : Édition 2019. https://www.stat.gouv.qc.ca/statistiques/populationdemographie/bilan2019.pdf\#page $=103$

Kent, P., Jensen, R. K., \& Kongsted, A. (2014). A comparison of three clustering methods for finding subgroups in MRI, SMS or clinical data: SPSS TwoStep Cluster analysis, Latent Gold and SNOB. BMC Medical Research Methodology, 14(1). https://doi.org/10.1186/1471-2288-14-113

Kuwabara, S. A., Van Voorhees, B. W., Gollan, J. K., \& Alexander, G. C. (2007). A qualitative exploration of depression in emerging adulthood: Disorder, development, and social context. General Hospital Psychiatry, 29(4), 317-324. https://doi.org/10.1016/j.genhosppsych.2007.04.001

Kypri, K., Cronin, M., \& Wright, C. S. (2005). Do university students drink more hazardously than their non-student peers? Addiction, 100(5), 713-714. https://doi.org/10.1111/j.13600443.2005.01116.x

Lamborn, S. D., \& Groh, K. (2009). A four-part model of autonomy during emerging adulthood: Associations with adjustment. International Journal of Behavioral Development, 33(5), 393-401. https://doi.org/10.1177/0165025409338440

Lanctôt, J., \& Poulin, F. (2018). Emerging adulthood features and adjustment: A person-centered approach. Emerging Adulthood, 6(2), 91-103. https://doi.org/10.1177/2167696817706024

Lee, S. M., Cho, S. H., Kissinger, D., \& Ogle, N. T. (2010). A typology of burnout in professional counselors. Journal of Counseling \& Development, 88(2), 131-138. https://doi.org/10.1002/j.1556-6678.2010.tb00001.x

Lee, T. K., Wickrama, K. A. S., O’Neal, C. W., \& Prado, G. (2018). Identifying diverse life transition patterns from adolescence to young adulthood: The influence of early socioeconomic context. Social Science Research, 70, 212-228. https://doi.org/10.1016/j.ssresearch.2017.12.001

Lehnart, J., Neyer, F. J., \& Eccles, J. (2010). Long-term effects of social investment: The case of partnering in young adulthood. Journal of Personality, 78(2), 639-670. https://doi.org/10.1111/j.1467-6494.2010.00629.x

Mandell, L., \& Klein, L. (2009). The impact of financial literacy education on subsequent financial behavior. Journal of Financial, Counseling and Planning, 20(1), 15-24.

Manning, W. D., Longmore, M. A., \& Giordano, P. C. (2010). Romantic relationships and academic/career trajectories in emerging adulthood, Working Paper Series 2009-02, https://doi.org/10.1017/CBO9780511761935.017

Marquand, A. F., Wolfers, T., Mennes, M., Buitelaar, J., \& Beckmann, C. F. (2016). Beyond lumping and splitting: A review of computational approaches for stratifying psychiatric disorders. Biological Psychiatry: Cognitive Neuroscience and Neuroimaging, 1(5), 433447. https://doi.org/10.1016/j.bpsc.2016.04.002

McCormick, C. M., Kuo, S. I.-C., \& Masten, A. S. (2011). Developmental tasks across the life span. In K. L. Fingerman, C. A. Berg, J. Smith, \& T. C. Antonucci (Eds.), Handbook of life-span development (pp. 117-139). Springer.

Mortimer, J. T., Zhang, L., Wu, C.-Y., Hussemann, J., \& Johnson, M. K. (2017). Familial transmission of educational plans and the academic self-concept: A three-generation 
longitudinal study. Social Psychology Quarterly, 80(1), 85-107. https://doi.org/10.1177/0190272516670582

Mulder, C. H., \& Clark, W. A. V. (2002). Leaving home for college and gaining independence. Environment and Planning A, 34(6), 981-999. https://doi.org/10.1068/a34149

Nagin, D. S. (2005). Group-based modeling of development. Harvard University Press.

Nelson, L. J. (2020). The theory of emerging adulthood 20 years later: A look at where it has taken us, what we know now, and where we need to go. Emerging Aadulthood, 1-10. https://doi.org/10.1177/2167696820950884

Oesterle, S., David Hawkins, J., Hill, K. G., \& Bailey, J. A. (2010). Men's and women's pathways to adulthood and their adolescent precursors, Journal of Marriage and Family, 72(5), 1436-1453. doi:10.1111/j.1741-3737.2010.00775.x

Osgood, D. W., Ruth, G. Eccles, J. S., Jacobs, J. E., \& Barber, B. L. (2005). Six paths to adulthood. In R. A. Settersten, F. F. Furstenberg Jr, \& R. G. Rumbaut (Eds.), On the frontier of adulthood: Theory, research, and public policy (pp. 320-355). University of Chicago Press.

Oxford, M. L., Lee, J. O., \& Lohr, M. J. (2010). Predicting markers of adulthood among adolescent mothers. Social Work Research, 34(1), 33-44. https://doi.org/10.1093/swr/34.1.33

Popenoe, D., \& Whitehead, B. D. (2001). Who wants to marry a soul mate? In D. Popenoe \& B. D. Whitehead, The state of our unions: The social health of marriage in America (pp.616). National Marriage Project.

Rankin, L. A., \& Kenyon, D. B. (2008). Demarcating role transitions as indicators of adulthood in the 21st century: Who are they? Journal of Adult Development, 15(2), 87-92. https://doi.org/10.1007/s10804-007-9035-2

Rauer, A. J., Pettit, G. S., Lansford, J. E., Bates, J. E., \& Dodge, K. A. (2013). Romantic relationship patterns in young adulthood and their developmental antecedents. Developmental Psychology, 49(11), 2159-2171. https://doi.org/10.1037/a0031845

Rauer, A. J., Pettit, G. S., Samek, D. R., Lansford, J. E., Dodge, K. A., \& Bates, J. E. (2016). Romantic relationships and alcohol use: A long-term, developmental perspective. $\begin{array}{llll}\text { Development } \quad \text { and } & \text { Psychopathology, } & \text { 773-789. }\end{array}$ https://doi.org/10.1017/S0954579416000304

Roisman, G. I., Masten, A. S., Coatsworth, J. D., \& Tellegen, A. (2004). Salient and emerging developmental tasks in the transition to adulthood. Child Development, 75(1), 123-133. https://doi.org/10.1111/j.1467-8624.2004.00658.x

Rosenberg, M., Schooler, C., Schoenbach, C., \& Rosenberg, F. (1995). Global self-esteem and specific self-esteem: Different concepts, different outcomes. American Sociological Review, 60(1), 141-156. https://doi.org/10.2307/2096350

Rouvès, V., \& Poulin, F. (2016). Romantic involvement and alcohol use in middle and late adolescence. International Journal of Adolescence and Youth, 21(1), 104-118. https://doi.org/10.1080/02673843.2013.831362

Schafer, J. L. (1999). Multiple imputation: A primer. Statistical Methods in Medical Research, 8(1), 3-15. https://doi.org/10.1177/096228029900800102

Serido, J., Pollitt, A. M., Muraco, J. A., Conger, K. J., \& Russell, S. T. (2018). Financial stress and drinking during the transition to adulthood. Emerging Adulthood, 7(6), 490-500. https://doi.org/10.1177/2167696818785555

Shanahan, M. J., Porfeli, E. J., Mortimer, J. T., \& Erickson, L. D. (2005). Subjective age identity and the transition to adulthood: When do adolescents become adults? In R. A. Settersten 
Jr., F. F. Furstenberg \& R. G. Rumbaut (Eds). On the frontier of adulthood: Theory, research, and public policy. University of Chicago Press.

Shek, D. T. L., Dou, D., \& Cheng, M. N. S. (2020). Transition from adolescence to emerging adulthood. The Encyclopedia of Child and Adolescent Development, 1-10. https://doi.org/10.1002/9781119171492.wecad325

Shulman, S., \& Connolly, J. (2013). The challenge of romantic relationships in emerging adulthood: Reconceptualization of the field. Emerging Adulthood, 1(1), 27-39. https://doi.org/10.1177/2167696812467330

Shulman, S., Scharf, M., Livne, Y., \& Barr, T. (2013). Patterns of romantic involvement among emerging adults: Psychosocial correlates and precursors. International Journal of Behavioral Development, 37(5), 460-467. https://doi.org/10.1177/0165025413491371.

Slutske, W. S. (2005). Alcohol use disorders among US college students and their non-collegeattending peers. Archives of General Psychiatry, 62(3), 321. https://doi.org/10.1001/archpsyc.62.3.321

Snyder, S. M., \& Rubenstein, C. (2014). Do incest, depression, parental drinking, serious romantic relationships, and living with parents influence patterns of substance use during emerging adulthood? Journal of Psychoactive Drugs, 46(3), 188-197. https://doi.org/ 10.1080/02791072.2014.914610

Tagliabue, S., Crocetti, E., \& Lanz, M. (2016) Emerging adulthood features and criteria for adulthood: Variable- and person-centered approaches. Journal of Youth Studies, 19(3), 374-388, https://doi.org/10.1080/13676261.2015.1074985

Tanner, J. L., Reinherz, H. Z., Beardslee, W. R., Fitzmaurice, G. M., Leis, J. A., \& Berger, S. R. (2007). Change in prevalence of psychiatric disorders from ages 21 to 30 in a community sample. The Journal of Nervous and Mental Disease, 195(4), 298-306. https://doi.org/10.1097/01.nmd.0000261952.13887.6e

Tatu, P., Pellet, J., Lang, F., Pichon, M., \& Coerchon, C. (1994). La SCL 90 R dans un échantillon de sujets francophones libres de troubles psychiatriques [The SCL-90- R in a sample of French-speaking adults without psychiatric disorders]. Annales Médico-Psychologiques, 152(3), 187-190.

Tkaczynski, A. (2017). Segmentation using two-step cluster analysis. In T. Dietrich, S. RundleThiele, \& K. Kubacki (Eds.), Segmentation in social marketing (pp. 109-125). Springer.

Vallières, E. F., \& Vallerand, R. J. (1990). Traduction et validation canadienne-française de l'échelle de l'estime de soi de Rosenberg. International Journal of Psychology, 25(2), 305316. https://doi.org/10.1080/00207599008247865

Vespa, J. (2017). The changing economics and demographics of young adulthood: 1975-2016. United States Census Bureau. Current population reports (P20-S79). https://www.census.gov/content/dam/Census/library/publications/2017/demo/p20579.pdf

Wagner, J., Lüdtke, O., Jonkmann, K., \& Trautwein, U. (2013). Cherish yourself: Longitudinal patterns and conditions of self-esteem change in the transition to young adulthood. Journal of Personality and Social Psychology, 104(1), 148-163. https://doi.org/10.1037/a0029680

Wright, D., Tone, A., Dyck, E., Aziz, M., Mehringer, A. M., Mozurkewich, E., ... \& Telner, J. I. (2005). SCL-90-R and 16PF profiles of senior high school students with excessive internet use. Canadian Journal of Psychiatry, 50, 407-414. 